\title{
Lead induces inflammation and neurodegenerative changes in the rat medial prefrontal cortex
}

\author{
Adekomi Damilare Adedayo ${ }^{1}$, Adewole Olarinde Stephen², Tijani Ahmad Adekilekun ${ }^{3}$, \\ Adeniyi Temidayo Daniel ${ }^{4}$ \\ ${ }^{1}$ Department of Anatomy, Faculty of Basic Medical Sciences, College of Health Sciences, Osun State University, Osogbo, Osun State, Nigeria \\ ${ }^{2}$ Department of Anatomy and Cell Biology, Obafemi Awolowo University, Ile-Ife, Osun State, Nigeria \\ ${ }^{3}$ Department of Anatomy, Ekiti State University, Ado Ekiti, Ekiti State, Nigeria \\ ${ }^{4}$ Department of Medical Laboratory Science, Kwara State University, Nigeria
}

\begin{abstract}
Objectives: Lead $(\mathrm{Pb})$ is a neurotoxicant heavy metal ubiquitously present in the eco-system. The precise mechanism by which $\mathrm{Pb}$ confers its deleterious effects on the cellular profile of the central nervous system remains unknown. The aim of this study was to investigate the effect of $\mathrm{Pb}$ on the medial prefrontal cortex (mPFC) using histological, immunohistological and morphological techniques.

Methods: Thirthy juvenile male Wistar rats were used in this study. The rats were randomly assigned into three groups. Group A served as the control group, Group B received $5 \mathrm{mg} / \mathrm{kg}$ Pb-nitrate ( $\mathrm{PbNO}_{3}$ ) orally for 21 days, and Group $\mathrm{C}$ received $5 \mathrm{mg} / \mathrm{kg} \mathrm{PbNO}_{3}$ and left for an additional 21 days to recover.

Results: There was a significant decrease in the number of normal neurons in the mPFC of the $\mathrm{PbNO}_{3}$-treated rats. The number of degenerating neurons significantly increased in the $\mathrm{PbNO}_{3}$-treated groups compared with the control group. A marked increase was observed in the number of astrocytic cell count in the $\mathrm{PbNO}_{3}$-treated groups compared with the control. The neuronal cells in the cytoarchitectural profile of the mPFC of the rats receiving $\mathrm{PbNO}_{3}$ showed marked neurodegenerative modification with features of distorted morphology, swollen and vacuolized cytoplasm, and features of either pyknotic or karyorrhectic nuclei. The cytoarchitecture of the mPFC of the rats in the control group preserved the normal histological outline suggestive of a normal and functional mPFC.

Conclusion: Exposure to $\mathrm{Pb}$ ingestion can result in significant inflammatory responses in the cytoarchitectural profile of the mPFC. Furthermore, 21 days of cessation of exposure to $\mathrm{PbNO}_{3}$ did not halt or reverse the deleterious effects of $\mathrm{Pb}$ on the $\mathrm{mPFC}$ of the rats, suggesting that Pb persists in the central nervous system of the rats.
\end{abstract}

Keywords: astrogliosis; cell death; heavy metals; neurodegeneration; pathology

Anatomy 2017;11(2):79-86 @2017 Turkish Society of Anatomy and Clinical Anatomy (TSACA)

\section{Introduction}

Lead $(\mathrm{Pb})$ is a lustrous bluish-silver colored metal heavy metal naturally present in human environment. ${ }^{[1,2]}$ According to Ahmed et al. (2013), ${ }^{[3]}$ exposure to $\mathrm{Pb}$ is unavoidable, as it occurs through many routes including contaminated air, water, soil, food and consumer products. Other sources of $\mathrm{Pb}$ are gasoline and house paint, which has been extended to lead bullets, plumbing pipes, pewter pitchers, storage batteries, toys and faucets. ${ }^{[4]} \mathrm{Pb}$ is commercially important as it is used in the manufacture of $\mathrm{Pb}$ acid storage electrical batteries, production of fusible metal alloys and foils, fabrication and synthesis of anti-friction metals and solder. ${ }^{[5]}$

Despite the enormous efforts put in place by the government and international health organizations in the developed and developing countries, exposure to PB persists as one of the major health challenge. ${ }^{[6]}$ 
$\mathrm{Pb}$ is known to be a neurotoxicant that competes with and impairs calcium ion signaling in nerve processes. ${ }^{[5,7,8]} \mathrm{It}$ inhibits the differentiation of neurons, suppresses longterm potentiation (LTP), alters the secretion of neurotransmitters, ${ }^{[9-11]}$ and also triggers the production of $\beta$ amyloid proteins. ${ }^{[12]}$ Other deleterious effects of $\mathrm{Pb}$ also include biochemical disruption, ${ }^{[13]}$ cellular alterations, ${ }^{[7,14]}$ metabolic ${ }^{[15]}$ and subclinical aberrations which ultimately lead to death in most cases. ${ }^{[16]}$ An example of this is the considerable number of children that died in the Zamfara $\mathrm{Pb}$ poisoning in Nigeria.

According to the descriptions of Liu et al. ${ }^{[17]}$ and Liu et al., ${ }^{[18]}$ tastrocytes and microglia are two of the four types of glial cells in the brain that are involved in the activation and regulation of the brain immunity in response to pathological conditions. ${ }^{[17]}$ In response to excitotoxicity, astrocytes and microglia enhance the production and release of inflammatory cytokines, increase the generation of reactive oxygen species, suppress the activities of antioxidants, thereby resulting in cellular loss or injury in the central nervous system (CNS). ${ }^{[19-22]}$

Although observations suggest that $\mathrm{Pb}$ is capable of inducing cellular dysfunction in the cortical regions of the brain, detailed mechanisms of actions remain largely unknown. The aim of the study was to observe the effect of $\mathrm{Pb}$ on the cytoarchitectural profile of the medial prefrontal cortex (mPFC) following exposure to $\mathrm{Pb}$-nitrate $\left(\mathrm{PbNO}_{3}\right)$.

\section{Materials and Methods}

All experimental procedures were in accordance with the guidelines for animal research outlined in the NIH Guidelines for the Care and Use of Laboratory Animals as approved by the Institute of Public Health, Obafemi Awolowo University, Ile-Ife, Nigeria.

The crystal salt of $\mathrm{PbNO}_{3}$ (Carlo Erba, Milano, Italy) was obtained from the Department of Biochemistry, Afe Babalola University, Ado Ekiti, Nigeria. The salt was dissolved in double distilled water and administered orally using metallic oral gavage. The solution was freshly prepared before each administration.

Thirty juvenile male Wistar rats (4 weeks old) weighing between 38 and $40 \mathrm{~g}$ were used for this study. The rats were obtained from the Department of Pharmacy, Obafemi Awolowo University, Ile-Ife, Nigeria. The rats were allowed to acclimatize for two weeks in the Animal Holdings of the Afe Babalola University, Ado-Ekiti, Nigeriai and housed in stainless steel cages $(48 \times 28 \times 20$ $\mathrm{cm})$ containing wood-shaving bedding. The beddings were changed once a week. The room was maintained on natural day/light cycle, at room temperature. The rats in all groups were allowed free access to standard laborato- ry rat pellet and clean drinking water was made available in polycarbonate bottles ad libitum.

Twenty-four hours after acclimatization, the thirty juvenile rats (now weighing about 40-44 g) were randomly assigned into three groups designated as Group A $(n=10)$, Group B $(n=10)$, and Group C $(n=10)$. The rats in Group A (control group) were treated with double distilled water, the rats in Group $\mathrm{B}$ ( $\mathrm{PbNO}_{3}$-treated) with 5 $\mathrm{mg} / \mathrm{kg}^{[23]} \mathrm{PbNO}_{3}$ by oral gavage for 21 days, and the rats in Group $\mathrm{C}$ (Pb-treated) were treated with $5 \mathrm{mg} / \mathrm{kg}$ of $\mathrm{PbNO}_{3}$ and left for 21 days to recover before they were sacrificed. No death of animal occurred during this study. At the end of the study, 10 rats from each group were exposed to an overdose of Nembutal (100 mg/kg, i.p.) and transcardially perfused with $4 \%$ paraformaldehyde, followed by $10 \%$ buffered formalin while the rats were in inverted position. Brain samples were excised and postfixed in $10 \%$ formalin with $30 \%$ sucrose. The mPFC (4.70-2.70 $\mathrm{mm}$ ventral and $4.70-2.70 \mathrm{~mm}$ dorsal to the bregma) was identified using the atlas of Paxinos and Watson, ${ }^{[24]}$ under dissection microscope. Subsequently, the $\mathrm{mPFCs}$ were paraffin-embedded and sectioned at $5 \mu \mathrm{m}$ on a microtome.

The immunohistochemical demonstration of astrocytes was performed according to the method of Ardalan et al. ${ }^{[25]}$ Briefly, floating sections were rinsed in tris buffer saline (TBS) containing $0.1 \%$ Triton X-100 for 30 min followed by blocking endogenous peroxidase using $30 \% \mathrm{H}_{2} \mathrm{O}_{2}$ and methanol dissolved in TBS for a further $30 \mathrm{~min}$. Antigen retrieval was done by heating the sections in the retrieval solution (Cat\#S1699; Dako, Glostrup, Denmark) dissolved in distilled water in the oven for $30 \mathrm{~min}$. Thereafter, the sections were rinsed three times in $1 \%$ bovine serum albu$\min (\mathrm{BSA})$ and $0.3 \%$ Triton- $\mathrm{X}$ in TBS solution for $10 \mathrm{~min}$. The sections were then incubated with a polyclonal rabbit anti-GFAP (Cat \#Z0334; Dako, Glostrup, Denmark) at 1:500 dilution with $1 \%$ BSA in TB buffer $50 \mathrm{mM}$ overnight at $4^{\circ} \mathrm{C}$, rinsed in TBS with $0.1 \%$ BSA and Triton X- 100 for $10 \mathrm{~min}$, and then incubated with polyclonal secondary goat anti-rabbit IgG antibody/HRP (Cat \#P0448; Dako, Glostrup, Denmark) at 1:200 dilution for 2 hours. Subsequently, the sections were washed three times in TBS for 10 minutes. The immunolabelling was performed using 3.3'-diaminobenzidine (DAB) solution for 1 minute. Lastly, the sections were mounted on the gelatin-coated slides and counterstained with $0.25 \%$ thionin solution (T3387; Sigma-Aldrich, St. Louis, MO, USA).

Images of the histological and immunohistochemical sections were captured using Leica DM 3000 (Leica, Wetzlar, Germany) with a cameroscope connected to a computer interface. The resolution of the cameroscope 
was 14 mega pixels. Histological and immunohistochemical images were photomicrographed at different magnifications and were examined using the Image Analysis and Processing for Java (Image J) program, public domain software sponsored by the National Institute of Health (USA). Normal neurons, degenerating neurons and astrocytes were counted in ten different non-overlapping sections from ten different rats in each group using high power field objective microscope lens of 40x using Apache OpenOffice Draw 3.4.1 (Apache Software Foundation, Forrest Hill, MD, USA) and Image J (NIH, USA) software. The statistical package GraphPad Prism Software (version 5.01; La Jolla, CA, USA) was used for data analysis. Cell count data were presented as mean $\pm \mathrm{SD}$. Non-parametric data were used directly in analysis using the Mann-Whitney $U$ and Kruskal-Wallis tests. Both Tukey's test and one-way analyses of variance (ANOVA) were used to compare the numbers of neurons, number of degenerating neurons, and number of astrocytic counts across the study groups.

\section{Results}

The number of normal neurons significantly decreased in the $\mathrm{PbNO}_{3}$-treated rats (Group $\mathrm{B}$ ) when compared with the control group $(\mathrm{p}=0.0002)$ (Figure 1). After 21 days of recovery, the number of normal neurons in Group C showed a significant decrease compared with the control group $(\mathrm{p}=0.0002)$. However, there was no significant difference in the number of normal neurons between Group B and Group C, suggesting that there was no improvement with recovery.

The number of degenerating neurons significantly increased in rats in the $\mathrm{PbNO}_{3}$-treated group (Group $\mathrm{B}$ ) compared with the control group $(\mathrm{p}=0.0001)$ (Figure 2). After 21 days of recovery, Group $\mathrm{C}$ also showed a marked significant increase in the number of degenerating neurons when compared with the control group $(\mathrm{p}=0.0001)$. On the other hand, there was also a significant difference $(\mathrm{p}=0.007)$ in the number of degenerating neurons between Group B and Group C.

The number of astrocytes showed a significant increase in the $\mathrm{PbNO}_{3}$-treated group (Group $\mathrm{B}$ ) compared with the control group $(\mathrm{p}=0.0001)$ (Figure 3). After 21 days of recovery, Group $\mathrm{C}$ also showed a significant increase in the number of astrocytes compared with the control group $(\mathrm{p}=0.0001)$. In addition, there was a significant decrease in the number of astrocytes between Group B and Group C ( $\mathrm{p}=0.0001)$.

We used Hematoxylin and Eosin stain to evaluate the cytoarchitecture of the mPFC after treatment with $\mathrm{PbNO}_{3}$ (Figure 4). The control group showed neurons with normal appearance, prominent basophilic cytoplasm, and small-sized neuroglia cells interspersed within the neuropil

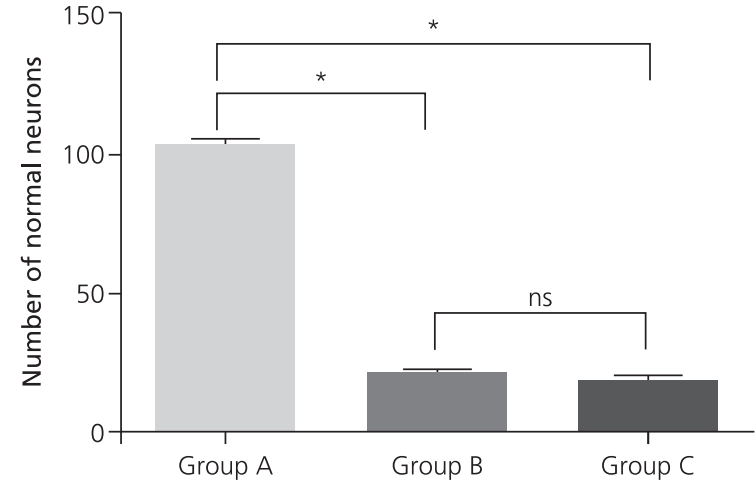

Figure 1. The number of normal neurons in the MPFC of the rats in in Groups A, B and C. * $p<0.001$; ns: non-significant.

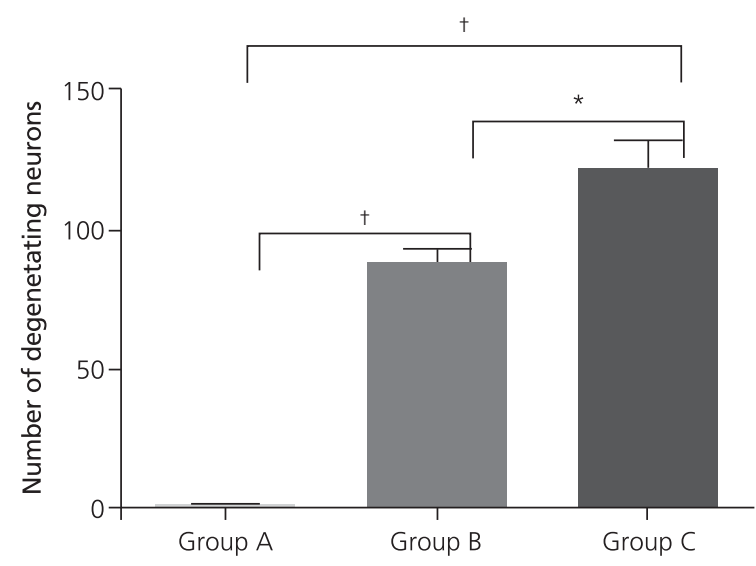

Figure 2. The number of degenerating neurons in the $\mathrm{mPFC}$ of the rats in Groups A, B and C. ${ }^{*} p<0.01 ;{ }^{\dagger} p<0.001$.

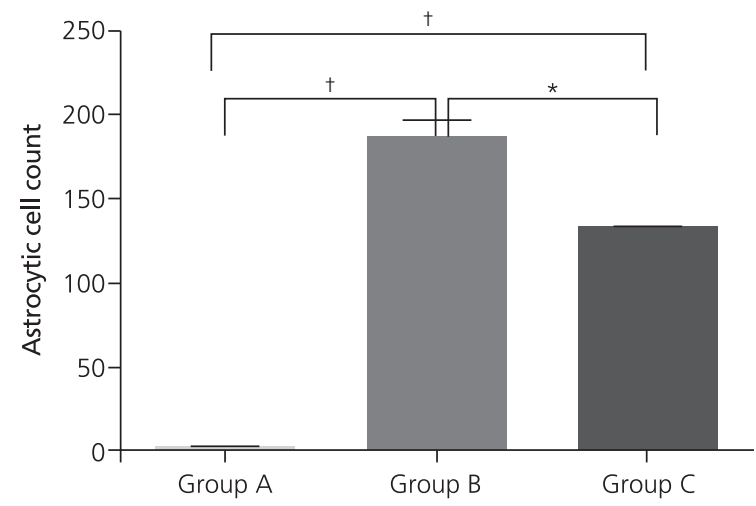

Figure 3. Astrocytic cell count in the mPFC of the rats in Groups A, B and C. ${ }^{*} p<0.01 ;{ }^{\dagger} p<0.001$.

(Figure 4a). $\mathrm{PbNO}_{3}$-treated group showed neurons with distorted morphology, swollen and vacuolized cytoplasm, and features of either pyknotic or karyorrhectic nuclei. Few of the neurons appeared with faintly stained cytoplasm 

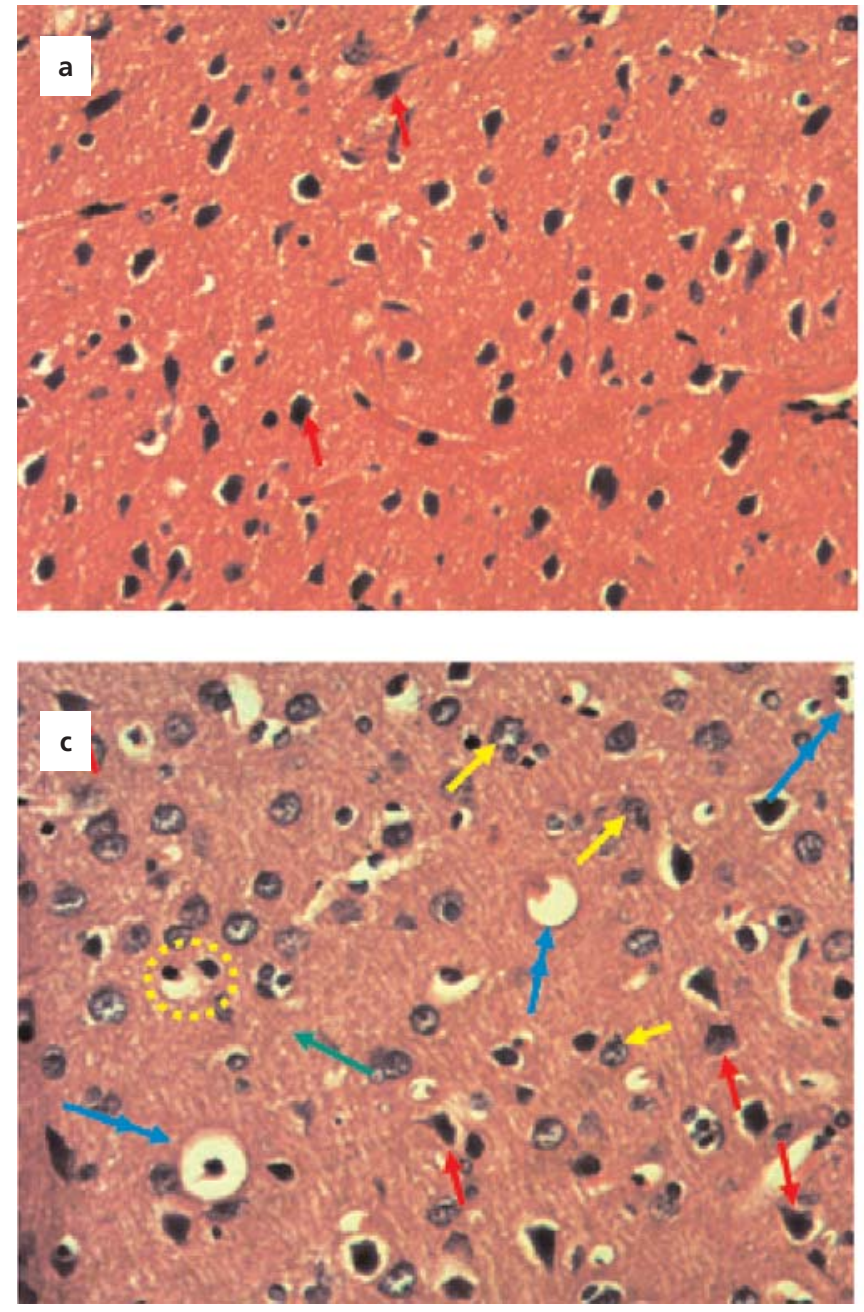

(Figure 4b). The recovery group showed similar cytoarchitectural outline to the $\mathrm{PbNO}_{3}$-treated; many neuronal cells with prominent cytoplasmic vacuolation and fragmented cytoplasm, with active-appearing microglial cell were observed (Figure 4c).

In the cresyl fast violet stained sections, distribution of Nissl bodies in mPFC neurons was investigated (Figure 5). The neurons in the control group were with no perineuronal cavitation or vacuolation, the neuronal cells were with darkly stained cytoplasm containing Nissl's substances (Figure 5a). In the $\mathrm{PbNO}_{3}$-treated group, mPFC neurons showed features of chromatolysis, fragmented cytoplasm and dispersed peri-nuclear Nissl deposits (Figure 5b). The $\mathrm{PbNO}_{3}$-treated group and the recovery group showed similar cytoarchitectural features (Figure 5c).

GFAP immunohistochemistry was used in this study to demonstrate astrocytic reaction as immunologic response to $\mathrm{Pb}$ exposure (Figure 6). A few GFAP immunoreactive astrocytes along with a large number of neurons were

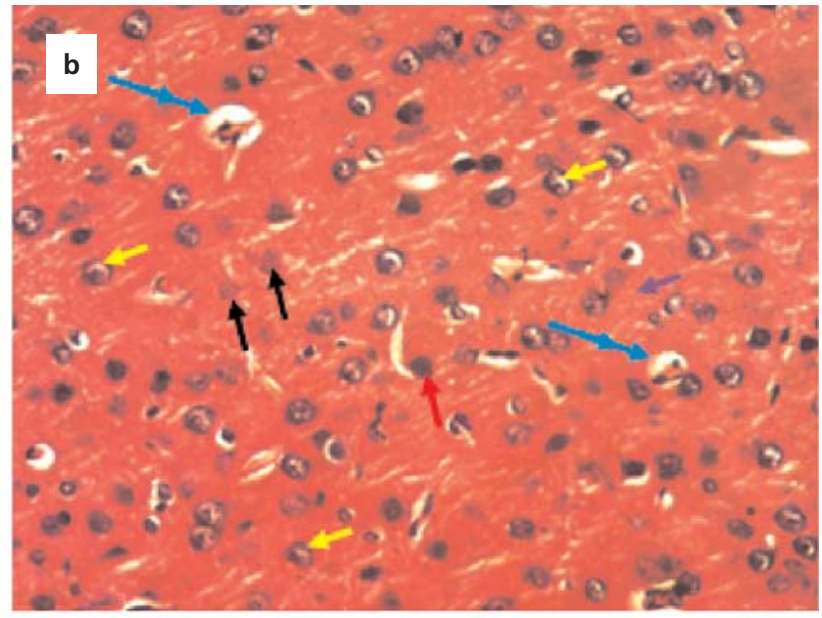

Figure 4. mPFC neurons in the (a) control, (b) PbNO3-treated, and (c) PbNO3-treated recovery groups. Normal neurons with normal appearance and with cytoplasm deeply stained with hematoxylin (red arrow); distorted and swollen membrane, vacuolated and degenerated neurons (double blue arrow); neurons with fragmented cytoplasm (yellow arrowhead) (Haematoxylene and Eosin stain, $\times 200$ ). [Color figure can be viewed in the online issue, which is available at www. anatomy.org.tr] observed in the mPFCs of the control group (Figure 6a). In the $\mathrm{mPFC}$ of the $\mathrm{PbNO}_{3}$-treated group, a significant increase was observed in the reactive astrocyte count compared with the control. The astrocytes were reactive, hypertrophied with their thick cytoskeletal processes (Figure 6b). In the recovery group (Group C), there was also a marked increase in the number of GFAP immunoreactive astrocytes compared with the control group, though the number of the astrocytes was not significantly different from the $\mathrm{PbNO}_{3}$-treated group (Figure 6c). The cytoplasmic processes of the astrocytes were seen with their complex cytoplasmic dendritic patterns, as a feature suggestive of inflammatory foci.

\section{Discussion}

In this present study, evidence from the histological, histochemical and immunohistochemical data showed that 21 days after exposure to $\mathrm{PbNO}_{3}$, the cellular profile of the $\mathrm{mPFC}$ did not show any significant improvement. 

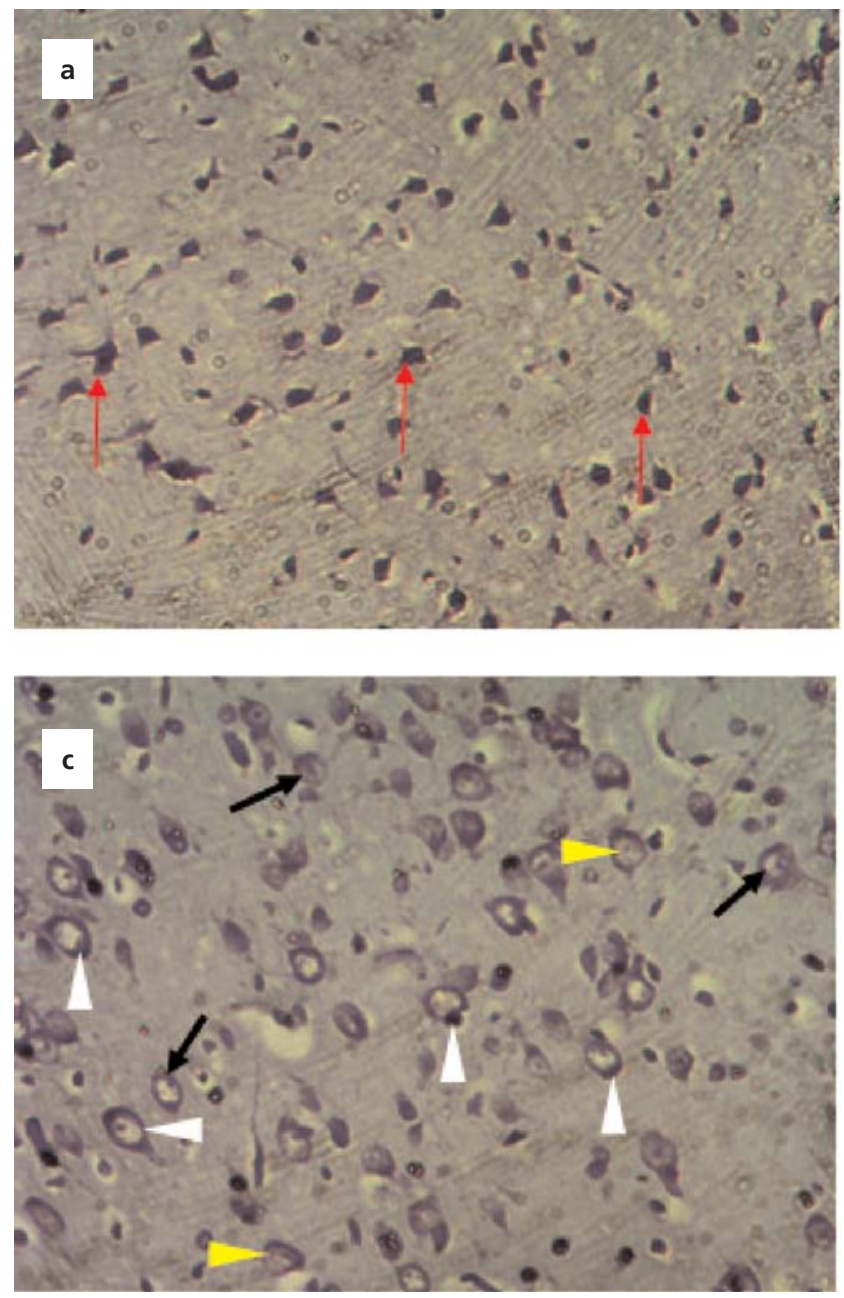

Undoubtedly, $\mathrm{Pb}$ continues to affect humanity because of its ubiquitous existence, extensive and wide industrial use, as well as anthropogenic activities. ${ }^{[26]} \mathrm{Pb}$ has been reported to cause significant neuronal damage in the CNS. ${ }^{[27-29]}$ Although the use of $\mathrm{Pb}$ has been significantly reduced, $\mathrm{Pb}$ exposure continues to be a risk, because level of $\mathrm{Pb}$ is constantly stable in the environment and no unhazardous threshold for $\mathrm{Pb}$ exposure has been established. ${ }^{[3,30]}$ The effects of $\mathrm{Pb}$ are particularly damaging to the developing nervous system, causing potentially irreversible learning and behavior deficits.

Since astrocytes modulate the activities of neural circuit in the healthy and diseased brain, examining astrocytic role is key to the understanding the effect of neurotoxin in the $\mathrm{CNS}^{[31]}$ In the brain and spinal cord, the normal anatomy of astrocytes regulates important physiological functions which include heterogeneous distribution of neurotransmitters, maintenance of the extracellular balance of ions, provision of energy metabolites to neurons, participation in

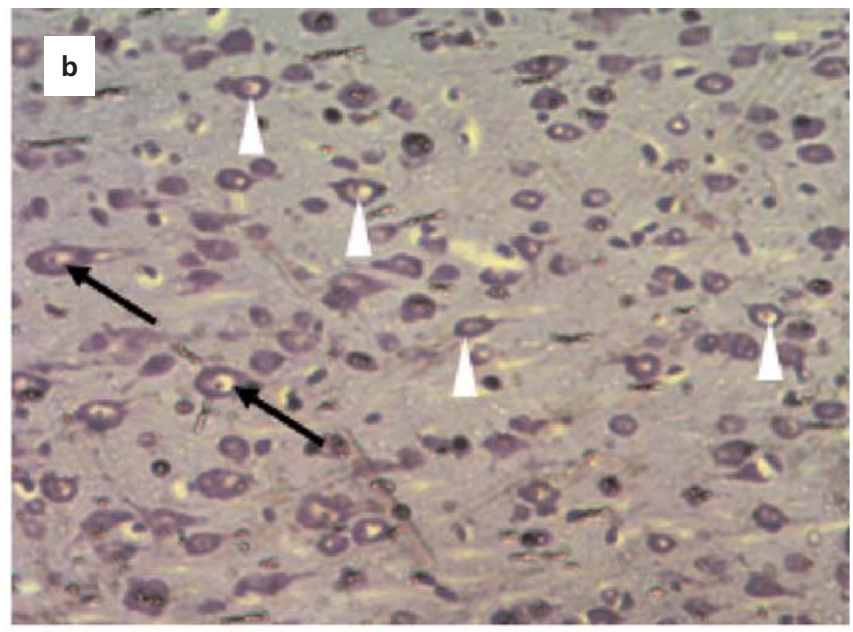

Figure 5. Nissl substance staining in MPFC neurons of the (a) control, (b) PbNO3-treated, and (c) PbNO3-treated recovery groups. In normal neurons with no perineuronal vacuolation or cavitation, the Nissl substances were anatomically placed within the neurons and the neurons were intact with their cytoplasmic contents (red arrow). Neurons with features of chromatolysis, fragmented cytoplasm and peri-nuclear Nissl deposits (white arrowhead); pyknotic neurons (black arrow); neurons with ruptured membrane (yellow arrowhead) (Cresyl fast violet staining, $\times 200$ ). [Color figure can be viewed in the online issue, which is available at www. anatomy.org.tr]

synaptic function and plasticity, and regulation of blood flow. ${ }^{[32]}$ On the other hand, as a result of the $\mathrm{PbNO}_{3}-$ induced neurotoxicity in this study, astrogliosis associated with degenerative neurons and inflammatory processes occurred in the $\mathrm{mPFC}$ of the rats. The biological process that lead to astrogliosis are not fully known. However, degenerating neurons have been suggested to be capable of inducing astrogliosis, and astrogliosis has been used as an indicating scale for evaluating neuronal damage. ${ }^{[33-36]}$

The present model of $\mathrm{Pb}$-induced inflammation in the cytoarchitectural profile of the $\mathrm{mPFC}$ in juvenile rats exposed to $\mathrm{PbNO}_{3}$ might explain the irreversible neuropathological and neurobehavioral anomalies associated with $\mathrm{Pb}$ exposure. ${ }^{[3,37]}$ The functional and structural integrity of the CNS is prone to various forms of insults and toxins that are capable of initiating cascades of deleterious responses. ${ }^{[34]}$ In this study, $\mathrm{Pb}$ exposure induced upregulation of GFAP expression and also modified the structural integrity of the neurons in the cytoarchitectural profile of 

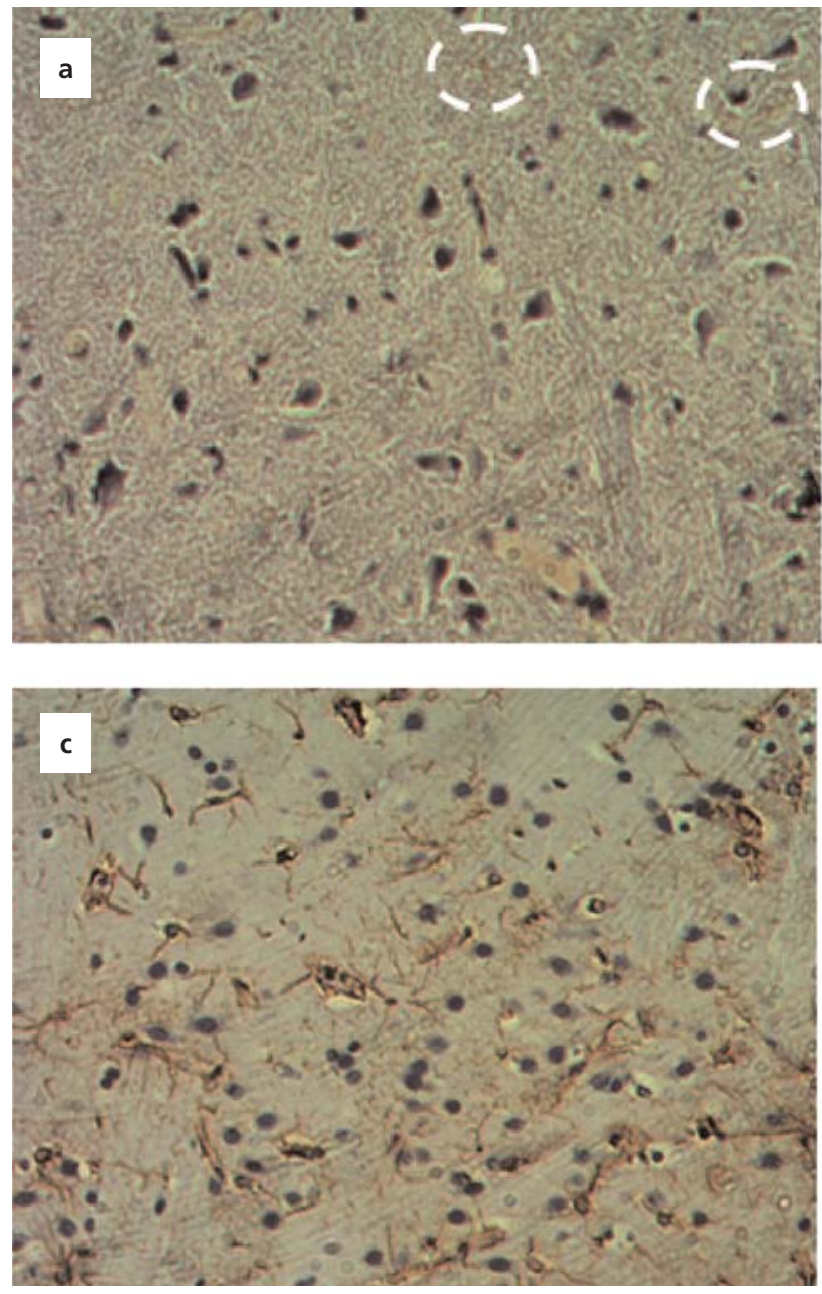

the $\mathrm{mPFC}$ of juvenile rats. In a previous study, increase in the expression level of GFAP in brain regions following $\mathrm{PbNO}_{3}$ treatment was documented. ${ }^{[38]}$ The astrocytic cell count was augmented following $\mathrm{PbNO}_{3}$ treatment suggesting that increased GFAP immunoreactivity can be an indication of the formation of gliosis as one of the mechanisms by which $\mathrm{Pb}$ induces its adverse effects on the CNS. In the CNS, astrocytes are abundant cells that provide support for neurons, contribute to the formation and function of synapses, thin-out synapses by phagocytosis, and participate in a wide range of homeostatic functions. ${ }^{[39-42]}$

One of the pivotal role of astrocytes is to respond to injury via an intricate process known as reactive gliosis, which causes cellular damage or loss of normal neuroprotective functions in the CNS following injury, trauma, or disease. ${ }^{[43]}$

In this study, marked damage was be observed in the cytoarchitecture of the $\mathrm{mPFC}$ dissected in the rats treated with $\mathrm{PbNO}_{3}$ (Figures $\mathbf{4 b}$ and $\mathbf{5 b}$ ). Similar neurodegenerative features were also present in $\mathrm{mPFCs}$ of the recovery

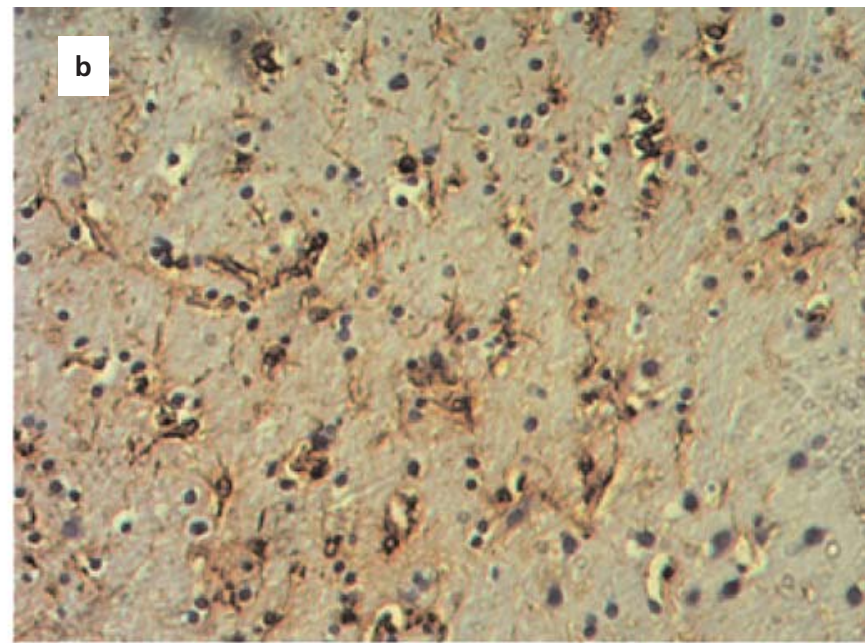

Figure 6. GFAP simmunohistochemical staining of neurons in the $\mathrm{mPFC}$ in the (a) control, (b) PbNO3-treated, and (c) PbNO3-treated recovery groups. Few astrocytes were observed in a (white dotted circle), and numerous GFAP immunoreactive astrocytes in $\mathrm{b}$ and $\mathrm{c}$. (GFAP immunohistochemical staining, $\times 200$ ). [Color figure can be viewed in the online issue, which is available at www. anatomy.org.tr]

group (Figures $\mathbf{4 c}$ and $\mathbf{5 c}$ ). These outcomes are similar to the neuropathological observations documented in previous studies. ${ }^{[4,45]}$

In a healthy CNS, calcium ions regulate a large number of cellular processes such as cell growth, differentiation, and synaptic activity. Although physiological increase in the levels of intracellular $\mathrm{Ca}^{2+}$ are typically crucial to cellular processes, excessive and irregular influx of $\mathrm{Ca}^{2+}$, and any other $\mathrm{Ca}^{2+}$ release from intracellular compartments, can impair $\mathrm{Ca}^{2+-}$-regulatory mechanisms and result in cell death. ${ }^{[27]}$ Considering the significantly increased number of astrocytes in the mPFCs of the $\mathrm{PbNO}_{3}$-treated and the recovery groups (Figures $\mathbf{6 b}$ and 6c), another possible justification is that, exposure to $\mathrm{PbNO}_{3}$ might have impaired the regulatory function of calcium on neuronal cell integrity and inhibited several intracellular biological activities. ${ }^{[46]}$

Neuronal cell death contributes to the basic neuropathology of various degenerative disorders of the 
CNS. ${ }^{[47,48]}$ In this study, $\mathrm{Pb}$ increased cell death in the $\mathrm{PFC}$ of the $\mathrm{PbNO}_{3}$-treated rats compared with the control. This partly shows the response adopted by the neurons of the $\mathrm{PFC}$ in the $\mathrm{Pb}$-treated rats, thus implying a definite response based on the extent of the insult which entirely relies on the cellular and genetic composition. On the other hand, it is possible that this might have occurred as a result of neuronal plasticity often seen in the different regions of the CNS due to the alteration in the ratio of DNA to RNA. ${ }^{[49]}$

Nissl staining is a quick and easy screen for neurodegeneration and the morphology of the dying neurons can be suggestive of apoptosis. Consistent with the integrity of cresyl fast violet as a marker of apoptosis, we observed in degenerating neurons peripheral deposits of Nissl substances with features of chromatolysis, suggesting that the neurons are undergoing apoptotic process. This result corroborates with the study of Dribben et al. ${ }^{[50]}$

Withdrawing the rats from further exposure to $\mathrm{Pb}$ did not bring any form of significant improvement in the cytoarchitectural profile of the $\mathrm{mPFC}$ of the rats compared with the control (Figures 4a, 4c, 5a, 5c, 6a and 6c). This effect in Group $\mathrm{C}$ may be due to the fact that $\mathrm{Pb}$ might not be completely metabolized and eliminated off by the excretory system of the rats in this group, as this could further generate excitotoxic characteristics in the neurons. ${ }^{[51]}$ It may as well be suggested that these observed alterations in the cellular integrity are due to excess $\mathrm{Pb}$ stored in the interneuronal spaces that inhibits oxygen utilization, thus reducing the production of the required level of ATP through the electron transport chain and modifying the morphology of the neuron to compensate for the available amount of energy present. ${ }^{[5,53]}$

Withdrawing the rats from further exposure to $\mathrm{Pb}$ did not bring any form of significant improvement in the cytoarchitecture of the mPFC compared with the control group (Figures $4 \mathbf{a}$ versus $\mathbf{4 c}$; $5 \mathbf{a}$ versus $\mathbf{5 c}$; $\mathbf{6 a}$ versus $\mathbf{6 c}$ ). This is in agreement with earlier studies that suggested that cellular improvement from $\mathrm{Pb}$ exposure was never complete. $^{[37,50]}$

\section{Conclusion}

Exposure to $\mathrm{Pb}$ confers deleterious and toxic effects on the cellular profile of the $\mathrm{mPFC}$ in juvenile male rats. Furthermore, 21 days withdrawal from further exposure to $\mathrm{Pb}$ does not restore the cytoarchitecture of the $\mathrm{mPFC}$.

\section{References}

1. Jaishankar M, Tseten T, Anbalagan N, Mathew BB, Beeregowda $\mathrm{KN}$. Toxicity, mechanism and health effects of some heavy metals. Interdiscip Toxicol 2014;7:60-72.
2. Kratzer J, Lettl C, Franke N, Gloor PA. The social network position of lead users. Journal of Productive Innovation Management 2016;3:201-16.

3. Ahmed MB, Ahmed MI, Meki AR, Abdraboh N. Neurotoxic effect of lead on rats: relationship to apoptosis. Int J Health Sci (Qassim) 2013;7:192-9.

4. Thürmer K, Williams E, Reutt-Robey J. Autocatalytic oxidation of lead crystallite surfaces. Science 2002;297:2033-5.

5. Nakata H, Nakayama SM, Oroszlany B, Ikenaka Y, Mizukawa H, Tanaka K, Harunari T, Tanikawa T, Darwish WS, Yohannes YB, Saengtienchai A, Ishizuka M. Monitoring lead $(\mathrm{Pb})$ pollution and identifying $\mathrm{Pb}$ pollution sources in Japan using stable $\mathrm{Pb}$ isotope analysis with kidneys of wild rats. Int J Environ Res Public Health 2017;14:pii.E56.

6. Naicker N, Mathee A, Barnes B. A follow-up cross-sectional study of environmental lead exposure in early childhood in urban South Africa. S Afr Med J 2013;103:935-8.

7. Lidsky TI, Schneider JS. Lead neurotoxicity in children: basic mechanisms and clinical correlates. Brain 2003;126:5-19.

8. Liu MC, Liu XQ, Wang W, Shen XF, Che HL, Guo YY, Zhao MG, Chen JY, Luo WJ. Involvement of microglia activation in the lead induced long-term potentiation impairment. PLoS One 2012;7: e43924.

9. Goldstein GW. Lead poisoning and brain cell function. Environ Health Perspect 1990;89:91-4.

10. Lasley SM, Gilbert ME. Rat hippocampal glutamate and GABA release exhibit biphasic effects as a function of chronic lead exposure level. Toxicol Sci 2002;66:139-47.

11. Gilbert ME, Kelly ME, Samsam TE, Goodman JH. Chronic developmental lead exposure reduces neurogenesis in adult rat hippocampus but does not impair spatial learning. Toxicol Sci 2005;86:365-74.

12. Monnet-Tschudi F, Zurich MG, Boschat C, Corbaz A, Honegger P. Involvement of environ-mental mercury and lead in the etiology of neurodegenerative diseases. Rev Environ Health 2006;21:105-17.

13. Godwin HA. The biological chemistry of lead. Curr Opin Chem Biol 2001;5:223-7.

14. Bazrgar M, Goudarzi I, Lashkarbolouki T, Elahdadi Salmani M. Melatonin ameliorates oxidative damage induced by maternal lead exposure in rat pups. Physiol Behav 2015;151:178-88.

15. Morris S, van Aardt WJ, Ahern MD. The effect of lead on the metabolic and energetic status of the Yabby, Cherax destructor, during environmental hypoxia. Aquat Toxicol 2005;75:16-31.

16. Duruibe JO, Ogwuegbu MOC, Egwurugwu JN. Heavy metal pollution and human biotoxic effects. International Journal of Physical Science 2007;2:112-8.

17. Liu W, Tang Y, Feng J. Cross talk between activation of microglia and astrocytes in pathological conditions in the central nervous system. Life Sci 2011;89:141-6.

18. Liu MC, Liu XQ, Wang W, Shen XF, Che HL, Guo YY, Zhao MG, Chen JY, Luo WJ. Involvement of microglia activation in the lead induced long-term potentiation impairment. PLoS One 2012;7: e43924.

19. Verstraeten SV, Aimo L, Oteiza PI. Aluminium and lead: molecular mechanisms of brain toxicity. Arch Toxicol 2008;82:789-802.

20. Kasten-Jolly J, Heo Y, Lawrence DA. Central nervous system cytokine gene expression: modulation by lead. J Biochem Mol Toxicol 2011;25:41-54.

21. Kasten-Jolly J, Pabello N, Bolivar VJ, Lawrence DA. Developmental lead effects on behavior and brain gene expression in male and female BALB/cAnNTac mice. Neurotoxicology 2012;33:1005-20. 
22. Kumawat KL, Kaushik DK, Goswami P, Basu A. Acute exposure to lead acetate activates microglia and induces subsequent bystander neuronal death via caspase-3 activation. Neurotoxicology 2014;41: $143-53$.

23. Adhikari N, Sinha N, Narayan R, Saxena DK. Lead-induced cell death in testes of young rats. J Appl Toxicol 2001;21:275-7.

24. Paxinos G, Watson C. The rat brain in stereotaxic coordinates. San Diego: Academic Press Elsevier; 2007. p. 340.

25. Ardalan M, Rafati AH, Nyengaard JR, Wegener G. Rapid antidepressant effect of ketamine correlates with astroglial plasticity in the hippocampus. Br J Pharmacol 2017;174:483-92.

26. Tchounwou PB, Yedjou CG, Patlolla AK, Sutton DJ. Heavy metals toxicity and the environment. EXS 2012;101:133-64.

27. Sanders T, Liu Y, Buchner V, Tchounwou PB. Neurotoxic effects and biomarkers of lead exposure: a review. Rev Environ Health 2009;24:15-45.

28. Flora G, Gupta D, Tiwari A. Toxicity of lead: a review with recent updates. Interdiscip Toxicol 2012;5:47-58.

29. Mason LH, Harp JP, Han DY. Pb Neurotoxicity: neuropsychological effects of lead toxicity. Biomed Res Int 2014:840547.

30. Hsiang J, Díaz E. Lead and developmental neurotoxicity of the central nervous system. Curr Neurobiol 2011;2:35-42.

31. Clarke LE, Barres BA. Emerging roles of astrocytes in neural circuit development. Nat Rev Neurosci 2013;14:311-21.

32. Sofroniew MV. Molecular dissection of reactive astrogliosis and glial scar formation. Trends Neurosci 2009;32:638-47.

33. Zhang R, Lu H, Tian S, Yin J, Chen Q, Ma L, Cui S, Niu Y. Protective effects of pre-germinated brown rice diet on low levels of $\mathrm{Pb}$-induced learning and memory deficits in developing rat. Chem Biol Interact 2010;184:484-91.

34. Burda JE, Sofroniew MV. Reactive gliosis and the multicellular response to CNS damage and disease. Neuron 2014;81:229-48.

35. Zuchero JB, Barres BA. Glia in mammalian development and disease. Development 2015;142;3805-9.

36. Olajide OJ, Akinola BO, Ajao MS, Enaibe BU. Sodium azideinduced degenerative changes in the dorsolateral prefrontal cortex of rats: attenuating mechanisms of kolaviron. Eur J Anat 2016;20:4764.

37. Eltony SA, Othman MA, Mohamed AA. Histological study on the effect of low level perinatal lead exposure on the cerebellar cortex of adult male albino rat. Egyptian Journal of Histology 2010;33:781-97.

38. Kumar P, Singh R, Nazmi A, Lakhanpal D, Kataria H, Kaur G. Glioprotective effects of Ashwagandha leaf extract against lead induced toxicity. BioMed Res Int 2014;2014:182029.

39. Sofroniew MV, Vinters HV. Astrocytes: biology and pathology. Acta Neuropathol 2010;119:7-35.
40. Chung WS, Allen NJ, Eroglu C. Astrocytes control synapse formation, function, and elimination. Cold Spring Harb Perspect Biol 2015;7:a020370.

41. Liddelow S, Barres B. Snapshot: astrocytes in health and disease. Cell 2015;162:1170-1170.e.1.

42. Liddelow SA, Guttenplan KA, Clarke LE, Bennett FC, Bohlen CJ, Schirmer L, Bennett ML, Münch AE, Chung WS, Peterson TC, Wilton DK, Frouin A, Napier BA, Panicker N, Kumar M, Buckwalter MS, Rowitch DH, Dawson VL, Dawson TM, Stevens B, Barres BA. Neurotoxic reactive astrocytes are induced by activated microglia. Nature 2017;541:481-7.

43. Aguzzi A, Barres BA, Bennett ML. Microglia: scapegoat, saboteur, or something else? Science 2013;339:156-61.

44. Struzyñska L, Bubko I, Walski M, Rafa6owska U. Astroglial reaction during the early phase of acute lead toxicity in the adult rat brain. Toxicol 2001;165:121-31.

45. Khanam S, Devi K. Effect of Withania somnifera root extract on leadinduced DNA damage. Journal of Food, Agriculture \& Environment 2005;3:31-3.

46. White LD, Cory-Slechta DA, Gilbert ME, Tiffany-Castiglioni E, Zawia NH, Virgolini M, Rossi-George A, Lasley SM, Qian YC, Basha MR. New and evolving concepts in the neurotoxicology of lead. Toxicol Appl Pharmacol 2007;225:1-27.

47. Cordeiro MF, Guo L, Coxon KM, Duggan J, Nizari S, Normando EM, Sensi SL, Sillito AM, Fitzke FW, Salt TE, Moss SE. Imaging multiple phases of neurodegeneration: a novel approach to assessing cell death in vivo. Cell Death Dis 2010;1:e3.

48. Lanni C, Racchi M, Memo M, Govoni S, Uberti D. p53 at the crossroads between cancer and neurodegeneration. Free Radic Biol Med 2012;52:1727-33.

49. Lee HS, Park JH, Kim SJ, Kwon SJ, Kwon J. A cooperative activation loop among SWI/SNF, gamma-H2AX and $\mathrm{H} 3$ acetylation for DNA double-strand break repair. EMBO J 2010;29:1434-45.

50. Dribben WH, Creeley CE, Farber N. Low-level lead exposure triggers neuronal apoptosis in the developing mouse brain. Neurotoxicol Teratol 2011;33:473-80.

51. Villeda-Hernández J, Méndez Armenta $M$, Barroso-Moguel R, Trejo-Solis MC, Guevara J, Rios C. Morphometric analysis of brain lesions in rat fetuses prenatally exposed to low-level lead acetate: correlation with lipid peroxidation. Histol Histopathol 2006;21:609-17.

52. Baranowska-Bosiacka I, Hlynczak AJ. The effect of lead ions on the energy metabolism of human erythrocytes in vitro. Comp Biochem Physiol C Toxicol Pharmacol 2003;134:403-16.

53. Maiti AK, Saha NC, Paul G. Effect of lead on oxidative stress, $\mathrm{Na}+\mathrm{K}+\mathrm{ATPase}$ activity and mitochondrial electron transport chain activity of the brain of Clarias batrachus L. Bull Environ Contam Toxicol 2010:84:672-6.

Correspondence to: Adekomi Damilare Adedayo, PhD Department of Anatomy, Faculty of Basic Medical Sciences, College of Health Sciences, Osun State University, Osogbo, Osun State, Nigeria Phone: +234803844 1671 e-mail: adedayo.adekomi@uniosun.edu.ng

This is an open access article distributed under the terms of the Creative Commons Attribution-NonCommercial-NoDerivs 3.0 Unported (CC BY-NCND3.0) Licence (http://creativecommons.org/licenses/by-nc-nd/3.0/) which permits unrestricted noncommercial use, distribution, and reproduction in any medium, provided the original work is properly cited. Please cite this article as: Adekomi DA, Adewole OS, Adekilekun TA, Daniel AT. Lead induces inflammation and neurodegenerative changes in the rat medial prefrontal cortex. Anatomy 2017;11(2):79-86. 